\title{
DA INCURSÃO DO MOVIMENTO AFROEQUATORIANO NO ESTADO: POSSIBILIDADES E LIMITAÇÕES
}

\author{
Johanna Katiuska Monagreda ${ }^{1}$
}

\section{Resumo}

$\mathrm{Na}$ América Latina, o discurso sobre mudança constitucional, iniciado nos anos setenta, foi penetrado pelo discurso do multiculturalismo ou pluralismo cultural. O objetivo deste artigo é discutir a influência do debate teórico e político sobre multiculturalismo em uma das demandas centrais dos afroequatorianos, que é o reconhecimento como "povo", e, ao tempo, apresentar e discutir as principais correntes teóricas que tentam explicar a incursão do movimento social afroequatoriano no Estado. Esse debate nos permitirá apontar caminhos para entender o processo de institucionalização da luta antirracista e dos direitos coletivos para população afrodescendente e refletir sobre as possibilidades de continuidade da política em tempos de mudança ideológica dos governos. A análise se baseia na revisão bibliográfica e na análise preliminar de entrevista a profundidade com integrantes do movimento afroequatoriano. Entendendo o movimento afroequatoriano como um processo organizativo, como seus próprios integrantes o definem, este exemplifica bem a complexidade do processo de politização da identidade étnico-racial e da relação Estado-Movimento. A exigência de encaixar na tríade: "cultura+linguagem+território" tem delimitado as ações do movimento afroequatoriano e sua vinculação com o Estado. Ao tempo que o caráter pouco institucionalizado das conquistas e o enfraquecimento do movimento no processo faz supor que mesmo com a garantia constitucional, os tímidos avanços em matéria de direitos coletivos, ações afirmativas e luta contra a discriminação racial, dependem em grande medida da permeabilidade dos governos a esses temas e da discricionariedade do funcionariado público em cada gestão.

Palavras chaves: Movimento afroequatoriano, Multiculturalismo, Políticas contra a desigualdade racial.

\section{Resumen}

En América Latina el discurso sobre cambio constitucional, iniciado en los años setenta, fue penetrado por el discurso del multiculturalismo o pluralismo cultural. El objetivo de este artículo es discutir la influencia del debate teórico y político sobre multiculturalismo en una de las demandas centrales de los afroecuatorianos, que es el reconocimiento como "pueblo" y presentar y discutir las principales corrientes teóricas que tratan de explicar a incursión del movimiento social afroecuatoriano en el Estado. Este debate nos permitirá señalar algunos caminos para entender el proceso de institucionalización de la lucha antirracista y por derechos colectivos para la población afrodescendiente y reflexionar sobre las posibilidades de continuidad de la política en tiempos de cambios ideológicos de gobierno. El análisis se basa en la revisión bibliográfica y el análisis preliminar de entrevistas a profundidad con integrantes del movimiento afroecuatoriano. Entendiendo el movimiento afroecuatoriano como un proceso organizativo, como sus propios integrantes lo definen, este ejemplifica bien la complexidad del proceso de politización de la identidad étnico-racial y de la relación Estado-Movimiento. La exigencia de encajar en la tríada: "cultura+lenguaje+territorio" delimita las acciones del movimiento afroequatoriano y su vinculación con el Estado. Al tiempo que, el carácter poco institucionalizado de las conquistas y el debilitamiento del movimiento en el proceso lleva a suponer que, aún

\footnotetext{
${ }^{1}$ Doutoranda em Ciência Política. Universidade Federal de Minas Gerais. Bolsista CAPES. johanna.monagreda@gmail.com.
} 
con la garantía constitucional, los tímidos avances en materia de derechos colectivos, acciones afirmativas y lucha contra la discriminación racial, dependen en gran medida de la permeabilidad de los gobiernos a esos temas y de la discrecionalidad del funcionariado público en cada gestión.

Palabras clave: Movimiento afroecuatoriano, Multiculturalismo, Políticas contra la desigualdade racial.

\begin{abstract}
In Latin America, the discourse on constitutional change, initiated in the 1970s, was penetrated by the discourse of multiculturalism or cultural pluralism. The objective of this article is to discuss the influence of the theoretical and political debate on multiculturalism in one of the central demands of Afro-Ecuadorians, which is the recognition as "people" and present and discuss the main theoretical currents that try to explain the incursion of the movement Afro-Ecuadorian society in the State. This debate will allow us to point out some ways to understand the institutionalization process of the anti-racist struggle and for collective rights for the Afro-descendant population and to reflect on the possibilities of continuity of politics in times of ideological changes of government. The analysis is based on the literature review and preliminary analysis of in-depth interviews with members of the Afro-Ecuadorian movement. Understanding the Afro-Ecuadorian movement as an organizational process, as its members define it, exemplifies well the complexity of the politicization process of ethnic-racial identity and the State-Movement relationship. The requirement to fit into the triad: "culture + language + territory" delimits the actions of the Afro-Ecuadorian movement and its link with the State. At the same time, the little institutionalized nature of the conquests and the weakening of the movement in the process leads to the assumption that, even with the constitutional guarantee, the timid advances in collective rights, affirmative actions and the fight against racial discrimination depend on a great measure of the permeability of governments to these issues and the discretion of the public official in each management.
\end{abstract}

Keywords: Afro-Ecuadorian movement, multiculturalism, policies against racial inequality.

\title{
1. DA INCURSÃO DO MOVIMENTO AFROEQUATORIANO NO ESTADO: POSSIBILIDADES E LIMITAÇÕES ${ }^{2}$
}

A partir do final dos anos 70, com Nicarágua, a América Latina começa um ciclo de mudanças constitucionais, onde a redefinição dos pactos nacionais se coloca, em muitos casos, como uma possibilidade de enfrentamento às crises sociopolíticas e de representação na região, seja nas novas

\footnotetext{
2 Agradecimentos: a Daniel Cañola, Sonia Viveros Padilla, Nibo Estuardo Delgado, José Chalá, Karen Vila Pavón, Juan Carlos Ocles, Alexandra Ocles, Juan Montaño, Catherine Chalá, Irma Bautista Nazareno e Mercedes Vargas por aceitar gentilmente conversar comigo durante horas sobre o movimento afroequatoriano, a incursão no Estado e as perspectivas a futuro. Agradeço também a Diógenes Diaz do movimento afrovenezuelano por me conectar com os irmãos e irmãs na diáspora do Equador.
} 
democracias em transição dos regimes autoritários, seja frente aos impactos de políticas neoliberais. $\mathrm{Na}$ América Latina, o discurso sobre constitucionalismo foi penetrado pelo discurso do multiculturalismo ou pluralismo cultural. Assim, ainda quando a América Latina era considerada uma exceção porque aparentemente não apresentava conflitos étnicos como os evidenciados em outros continentes, as questões étnico-raciais foram colocadas nas reformas constitucionais ao ponto de alguns autores caracterizarem esse período como de multiculturalismo constitucional (VAN COTT, 2008; 2009), de reformas na cidadania multicultural (HOOKER, 2005), ou de neoliberalismo multicultural (HALE, 2002).

Seguindo Van Cott (2009), em nenhum país da região a demanda das organizações de grupos étnicos por direitos especiais e reconhecimento foi o que motivou a mudança constitucional. Mas quando as crises políticas na década de 1990 suscitaram apelos entre as elites para a reforma constitucional, os movimentos indígenas em muitos países estavam bem posicionados para aproveitar a janela política e pressionar por mudanças institucionais (KINGDON,1984; LOVEMAN, 2014). Não obstante, os movimentos de afrodescendentes são os que, em geral, encontraram mais resistência para ver a suas demandas reconhecidas.

Vários fatores explicam essa demora em considerar as lutas dos afrodescendentes. O multiculturalismo, na teoria e na prática, pressupõe a existência de um povo reconhecível e totalmente distinguível das elites nacionais, seja como grupos étnicos, grupos raciais ou minorias nacionais (KLYMICKA, 1995). Ou seja, o multiculturalismo precisa, para se justificar, de um grupo distinguível, o que Greene (2007), citado por Rahier e Prosper (2014), chamou “a santíssima trindade do povo multicultural", segundo o qual o grupo deve cumprir com o critério “cultura+linguagem+território". Enquanto a população indígena conseguia se encaixar perfeitamente nesse critério, os afrodescendentes na América Latina, na ausência de algum desses componentes consequência dos processos de miscigenação e assimilação forçada, costumam ser considerados como totalmente absorvidos dentro do Estado-Nação.

Além desse critério que a teoria salienta, a força do movimento indígena em vários países da América Latina, principalmente na região andina, ganhou visibilidade e reconhecimento no interno dos seus países e no âmbito internacional, definindo os termos da discussão sobre reconhecimento e direitos coletivos. O posicionamento da diferença indígena como enquadramento hegemônico para se pensar o multiculturalismo permaneceu durante o processo de mudanças constitucionais, de modo que as reformas tiveram na sua concepção e base as formas que adquiria as demandas por 
reconhecimento indígena. Quando os afrodescendentes começam a aparecer como sujeitos de direitos é por uma "reflexão tardia", como é o caso da Lei 70 da Colômbia (1993), ou como um "adicional" derivado do reconhecimento indígena, como aconteceu com a inclusão de direitos coletivos na Constituição de Equador em 1998 (WALSH, 2012).

A Terceira Conferência Mundial contra o Racismo, a Discriminação Racial, a Xenofobia e Formas Correlatas sediada em Durban no ano 2001 marcou uma mudança com relação a centralidade da discussão sobre afrodescendentes para as políticas étnico-raciais, particularmente com a recomendação de criação de espaços institucionalizados de inclusão da temática da discriminação racial dentro do Estado, contida no Plano de Ação de Durban. Em decorrência desta Conferência, 16 países da região teriam criado instâncias dedicadas ao tratamento das questões raciais e de discriminação racial e étnica (RIBEIRO, 2012).

Desde a Constituição de 1998, o Equador assume uma orientação multicultural. Com a Constituição vigente de 2008, promulgada dentro do projeto político da "Revolução Cidadã", o Equador mantém o reconhecimento constitucional da população afroequatoriana como um povo; a utilização do termo "afroequatoriano" em lugar de "negro" - considerado termo que guarda uma forte carga pejorativa associada ao passado colonial -;e o reconhecimento de direitos coletivos para a população afrodescendente, mas, enquanto a Constituição de 1998 deixava em aberto a aplicação dos direitos coletivos para os afroequatorianos na interpretação daqueles com poder para os fazer cumprir ou não, na Constituição de 2008 se reconhece de forma inequívoca a titularidade de direitos para os afroequatorianos (JOHNSON, 2007; RAHIER; PROSPER, 2014).

A literatura e a prática da política multicultural se baseiam no pré-requisito de uma identidade étnica diferente da identidade nacional, dai que o reconhecimento como povo aparecesse como uma condição para adquirir direitos coletivos. De fato, em muitos países da região, nos casos onde negros ganharam direitos coletivos nas suas respectivas constituições nacionais foram aqueles onde eles conseguiram se colocar como um grupo étnico, isto é, grupos "autóctones" com uma "identidade cultural distintiva" em um sentido retórico semelhante à população indígena (HOOKER, 2005). Isto é especialmente palpável no caso equatoriano. onde as dinâmicas de mobilização e as estratégias de enquadramento do movimento indígena tem impactado notoriamente no processo de institucionalização das demandas do movimento negro dentro do Estado.

O reconhecimento dos afroequatorianos como povo fundante da nação equatoriana, se coloca como uma demanda importante para os negros do Equador, em parte, pela orientação 
multiculturalista dos anos noventa tanto dos governos da época quanto das agências internacionais financistas, que acabaram definindo os moldes da discussão sobre direitos para grupos sob noções de indigeneidade, mas também alguns fatores próprios da dinâmica nacional deram esse enfoque. Entre eles, a proximidade de atores do movimento afroequatoriano com o movimento indígena, pelo que afroequatorianos acabaram replicando repertórios e estratégias de ação com as quais os indígenas tiveram sucesso (VAN COT'T, 2008; ANTÓN, 2011); a necessidade de compensar a exclusão dos negros do relato da fundação da Nação ${ }^{3}$ (RAHIER; PROSPER, 2014; DE LA TORRE, 2005), e, porque se entendia que a possibilidade de ganhar direitos coletivos estaria atrelada ao reconhecimento como um povo distinguível da elite nacional.

Consequentemente, o processo de institucionalização das suas demandas e de procura por direitos coletivos e políticas de ação afirmativas exigiu para o movimento afroequatoriano a construção de um sujeito coletivo, que para o caso foi possível a partir da noção de povo. A noção de povo negro ou afroequatoriano.

\subsection{A NOÇÃO DE POVO NEGRO OU AFROEQUATORIANO}

Pueblo tem, pelo menos, dois sentidos na Constituição equatoriana de 2008. O povo é a nação, e é o "outro" institucionalizado. A primeira noção de povo dentro da Constituição equatoriana está vinculada à concepção unitária do Estado. É explicita em enunciados como "Nosotras y nosotros, el pueblo soberano del Ecuador", ou na afirmação "La soberanía radica en el pueblo".

Já o status de "povo" para os afroequatorianos significa que são o "Outro" institucionalizado (RAHIER, 2012). No reconhecimento como povo, está implícito o entendimento de que os negros no Equador configurariam um sujeito da nação diferente ao sujeito "branco-mestiço". E essa diferença justifica a legitimidade de direitos coletivos. Supõe que os negros no Equador seriam identificáveis como um grupo étnico, com práticas culturais próprias, com traços sociopolíticos comuns: "história, organização social, estrutura de parentesco, modos e práticas tradicionais de produção, territorialidade, entre outros elementos como cosmovisão, espiritualidade, pensamento e conhecimento ancestral que redefinem a complexidade do seu mundo” (ANTÓN, 2011, p. 182).

${ }^{3}$ Equador incorporou "o índio" dentro do seu relato de identidade nacional, dentro do seu relato da nação mestiça, mas a diferença de outros países como Venezuela, Brasil ou Cuba, manteve à população negra fora do relato de construção da nação (RAHIER; PROSPER, 2014; DE LA TORRE, 2005). 
O reconhecimento como povo foi interpretado por todos os entrevistados do movimento afroequatoriano como uma conquista. Isso porque a noção de povo lhes permite pleitear a titularidade de direitos coletivos. De fato, o reconhecimento constitucional como povo lhes abre a possibilidade de ter voz na esfera pública em um momento em que o projeto político encoraja a inclusão dos sujeitos que se definem em "termos étnicos" como sujeito-cidadão moderno (WALSH, 2012).

Assim:

A demanda por reconhecimento e fortalecimento da identidade coletiva dos afroequatorianos lhes permitiu o reconhecimento como "povo", cujo traço distintivo é a etnicidade. Desse modo os afroequatorianos tem configurado uma identidade coletiva do tipo político e de carácter estratégico, que lhes permite reivindicar a proteção da sua identidade, histórica, territórios, cosmovisões e formas especificas de desenvolvimento e participação. Esses elementos próprios do povo afroequatoriano são demandados como um conjunto de direitos culturais ou coletivos (ANTÓN, 2011, 182-183, tradução própria ${ }^{4}$ ).

Como nota Van Cott $\left(2009,277^{5}\right)$ : "Essa linguagem é interessante porque os negros são identificados como 'povos', uma designação geralmente usada por ativistas indígenas para distinguir índios de "minorias étnicas"'. Equador é o primeiro país da América Latina que dá status constitucional de povo aos afrodescendentes, junto com Bolívia são os únicos países da região em pensar os negros ou afrodescendentes como um povo. Isto não é por acaso, pois a noção de povo faz parte da linguagem dos movimentos indígenas, com uma longa trajetória de consolidação, que por vezes tem influenciado a forma de organização dos movimentos afrodescendentes nesses países: "Embora os movimentos indígenas na Colômbia e no Equador tenham liderado as campanhas pelo reconhecimento oficial da diversidade racial e étnica, grupos negros nos dois países e em toda a região usaram essas constituições para chamar a atenção para sua singularidade cultural" (JOHNSON, 2007, 58, tradução própria ${ }^{6}$ ).

\footnotetext{
${ }^{4}$ No original: La demanda por un reconocimiento y un fortalecimiento de la identidad colectiva de los afroecuatorianos les ha permitido el autoreconocimiento como "pueblo", cuyo rasgo distintivo es la etnicidad. De este modo los afroecuatorianos han configurado una identidad colectiva de tipo político y de carácter estratégico, lo que les lleva a reivindicar la protección de su identidad, historia, territorios, cosmovisiones y formas específicas de desarrollo y de participación. Estos elementos propios del pueblo afroecuatoriano son demandados como un conjunto de derechos culturales o colectivos (ANTÓN, 2011, p. 182-183).

${ }^{5}$ No original: This language is interesting in that blacks are identified as "peoples," a designation usually used by indigenous activists to distinguish Indians from "ethnic minorities." (VAN COTT, 2009, p. 277)

${ }^{6}$ No original: Although the Indigenous movements in Colombia and Ecuador have led the campaigns for officially recognizing racial and ethnic diversity, Black groups in both countries and throughout the region have used these constitutions to call attention to their cultural uniqueness (JOHNSON, 2007, 58).
} 
De certa forma, o movimento indígena é a referência de movimento organizado para o movimento afroequatoriano. Inclusive, a trajetória de institucionalização do movimento que levou à conformação da Confederação de Nacionalidades Indígenas do Equador (CONAIE), a maior organização indígena do Equador fundada em 1986, é avaliada como positiva porque se entende que eles conseguem impactar o Estado. Em conversações com ativistas do movimento afroequatoriano, algumas pessoas referiram que observam que as hierarquias próprias da cultura indígena são incorporadas ao processo de tomada de decisões dentro da administração pública, em oposição às organizações afroequatorianas que tendem a ser mais informais, explicando assim o maior sucesso das organizações indígenas na negociação com o Estado.

Para De La Torre (2005) e De La Torre e Antón (2012), com a criação da Corporación para el Desarrollo Afroecuatoriano (CODAE), o movimento afroequatoriano estaria procurando a sua própria inclusão corporativista no Estado, seguindo o exemplo do movimento indígena com a criação da CONAIE. Segundo Antón (2011), o processo de institucionalização das demandas do movimento afrodescendente tem relação com o processo de institucionalização do movimento indígena no Equador. De fato, as primeiras instituições e os primeiros projetos que o Estado cria para atender aos afroequatorianos são compartilhadas com o movimento indígena na lógica da diferença cultural. Isso sem dúvida deixa um legado na formas de organização posteriores.

Contudo, a noção de povo não é apenas produto da influência do movimento indígena, se pensar como um povo tem sido fundamental no processo de politização do pertencimento étnicoracial na conformação do processo organizativo afroequatoriano. A revalorização política da identidade afroequatoriana implica um "complexo processo de construção étnica partindo de práticas discursivas que aludem a condições ancestrais, históricas e políticas da cultura negra ou afroamericana" (ANTÓN, 2011, 887) e, portanto, a confirmação como um povo é também um processo consciente e ativo de identificação.

Esse processo de politização, quer dizer, tornar política uma dimensão da vida que era considerada estritamente cultural ou desconsiderada do espaço público, acontece no encontro com outros iguais na construção de um processo organizativo (movimento social) ou de uma ação coletiva; acontece por influência de intelectuais orgânicos, mas também pela agência do próprio

\footnotetext{
${ }^{7}$ No original: complejo proceso de construcción étnica partiendo desde prácticas discursivas que aluden a condiciones ancestrales, históricas y políticas de la cultura negra o afroamericana (ANTÓN, 2011, p. 88)
} 
Estado, pela ação de transnacionais, e pela igreja no caso Equatoriano, no que Antón (2011) chama de "agentes estimuladores de perspectivas coletivas de autoidentificação".

Principalmente, o Estado detém esse poder de agente estimulador de perspectiva coletiva de autoidentificação tanto na construção e reprodução da memória coletiva ou do mito fundacional, no que se inclui e exclui dos censos como características da população, nas políticas educativas e migratórias, na negação ou consolidação de direitos, etc.

Nos anos 1990, o projeto neoliberal está em auge na América Latina e justamente o fato das políticas neoliberais produzirem um aumento na pobreza e o enfraquecimento do Estado, consequência da ideologia do Estado mínimo, fez com que surja a organização de alguns grupos sociais como indígenas, ambientalistas e afrodescendentes. Assim, o discurso multiculturalista nas comunidades negras e indígenas sob a influência da banca multilateral e das organizações transnacionais interessadas no discurso de superação da pobreza intervindo nas comunidades indígenas e negras impacta na organização política das comunidades. Surgem, portanto, organizações étnicas profissionalizadas em interesse de acessar aos recursos disponíveis pela cooperação internacional. Equador é um caso onde os desafios do multiculturalismo e o avanço das políticas neoliberais vão junto. Assim, a origem da organização afrodescendente e atenção do Estado deixaram legados que logo aparecem, inclusive no projeto político da chamada "Revolução Cidadã".

Um dos problemas de pensar o sujeito das políticas a partir da diferença cultural ou da diversidade é que se desvia o foco das mudanças estruturais (VAN COTT, 2009). Nesse sentido, segundo Walsh (2012), ainda que a Revolução Cidadã representou para o movimento afroequatoriano uma janela de oportunidade política para a inclusão, não foi uma inclusão de um projeto político emancipador, mas a inclusão de pessoas pertencentes aos grupos étnicos-raciais como indivíduos junto com uma visão estereotipada e folklorizada dos grupos étnicos-racias dentro do Estado. Um exemplo colocado por Walsh (2012) é que o lançamento do Ano dos Afrodescendentes em julho de 2011 pelo Ministério dos movimentos sociais foi apresentado como uma festa de música e dança.

Contudo, a complexidade da inclusão deve ser pensada segundo os contextos nacionais. Enquanto o reconhecimento das danças e das músicas patrimônio das comunidades afrodescendentes pode colocar as demandas dos afroequatorianos dentro de uma agenda inócua de demandas por diversidade cultural e da reprodução de manifestações culturais, no caso equatoriano, também dá às tradições de matriz africana um lugar que não lhe correspondia dentro da construção 
da identidade nacional. Lembremos que no Equador a ideia de nação mestiça foi pensada como a mistura dos indígenas e o colonizador, com exclusão do povo negro.

Em todo caso, a reescrita da história da nação a partir do protagonismo da população negra se abriu como possibilidade de questionar a memória pública (HOOKER, 2005). De modo que, para o caso equatoriano, a despeito da proximidade com o discurso da diversidade cultural, o movimento tem articulado uma agenda de demandas por mudanças estruturais na educação, no âmbito laboral e na garantia do território, principalmente.

A literatura sobre o movimento afroequatoriano nos apresenta pelo menos três correntes de análise sobre a relação do movimento afroequatoriano com o Estado: Catherine Walsh, Rahier e Prosper, que propoem uma análise da revalorização da identidade; Carlos De La Torre (2005), que explica a relação do Estado e o movimento afroequatoriano dentro da tese do corporativismo; e John Antón (2011), que propõe uma leitura a partir da teoria dos movimentos sociais salientando o poder de agência do movimento.

\subsection{LEITURA DA IDENTIDADE CULTURAL}

Dentro dessa corrente de análise, os autores tendem a observar a revalorização étnica e estratégias essencialistas como elementos chaves para a ação.

De fato, as reivindicações associadas à cultura e a proposta de novas formas de interculturalidade fazem parte da luta do movimento afroequatoriano. A valorização racial se coloca como uma estratégia de construção de um contra-discurso que faça frente ao discurso hegemônico carregado de estereótipos e preconceitos contra a população negra, como Whitten e Quiroga (1998) identificam no esforço do movimento negro do Equador dos anos noventa de contestar a frase "mejorar la raza" [melhorar a raça] com a frase "hacer valer la raza" [valorizar a raça].

Outro elemento que tem sido salientado como fundante da organização do movimento afroequatoriano é a luta pela inclusão e pela existência. Para Walsh (2012), a premura por resolver questões fundamentais da vida tem o efeito de que aspectos menos tangíveis como a transformação do Estado tem ficado em segundo plano, consequência principalmente das condições de pobreza que essa população enfrenta. Assim, casos de vulneração da vida, de violência policial têm movimentado mais do que outras faces da discriminação. 
$\mathrm{Na}$ prática, as organizações do movimento negro do Equador têm assumido distintas bandeiras que atravessam a luta pela valorização cultural e a conservação da história, a luta pela garantia de direitos e a inclusão para a população negra, e a inserção no Estado como reivindicação e expansão dos direitos políticos.

\subsection{CORPORATIVISMO E PATERNALISMO}

A incursão do movimento social afroequatoriano no Estado tem sido analisado como um caso de corporativismo estatal e cooptação (De La TORRE, 2005; De La TORRE; ANTÓN, 2012), paternalismo político (De La TORRE, 2005), e/ou inclusão representativa e funcional (WALSH, 2012). Em todos os casos, os autores focam nos efeitos perversos da aproximação dos movimentos sociais dentro do Estado.

A tese corporativista sobre as organizações sociais do movimento afroequatoriano, salienta o poder de agência do Estado, da Igreja e da Cooperação internacional e a Banca multilateral para definir as características do processo organizativo afroequatoriano e para promover a ação coletiva (ANTÓN, 2011).

Carlos de la Torre (2005) é um dos principais defensores da tese do corporativismo para explicar o surgimento do movimento afroequatoriano. Segundo De la Torre (2005), no corporativismo, o Estado estimula a organização porque torna a conformação de grupos formalmente organizados uma exigência para ser reconhecidos como interlocutor válido de uma coletividade, provocando incentivos para a organização, uma vez que o ator social no corporativismo tem que ser reconhecido pelo Estado. Segundo esta abordagem, o movimento afroequatoriano ou grupos de interesses em torno à identidade negra no Equador teriam sido criados ou promovidos pelo Estado, quem controla, contém e regula a sua atuação (De la TORRE; ANTÓN, 2012).

$\mathrm{Na}$ análise de De la Torre (2005), os afroequatorianos não acedem ao Estado, ou não demandam do Estado na sua condição de cidadãos, mas aproveitando redes personalistas ou paternalistas. Isso acontece porque "no Equador, como na maioria das nações latinoamericnas, a cidadania é fraca e as pessoas comuns usam estratégias baseadas em paternalismo e corporativismo 
para negociar acesso a recursos dos quais estão excluídas" (De la TORRE, 2005, 61, tradução própria $\left.^{8}\right)$.

Essa forma de vinculação com o Estado dificulta uma compreensão estrutural da dominação, não promove uma compreensão de direitos, mas de um acesso a prerrogativas especiais possível graças às redes de contatos certas. Dessa forma, o Estado incorpora os atores que lideram os processos de demandas, organiza a disputa, define quem são os atores legítimos, e é com esses grupos que negocia a transferência de recursos, de modo que os fortalece enquanto ignora, reprime ou inclusive impossibilita a existência de outros, define qual o tipo de reivindicação possível. No corporativismo, o movimento social é cooptado e a protesta social é canalizada e regulada através de um mecanismo institucional.

Segundo De la Torre e Antón (2012), a inclusão só produziu visibilidade, pois não aumentou a capacidade de ação coletiva, nem há implementação efetiva de políticas públicas, por demais, o movimento teria perdido atores importantes esvaziando o movimento social.

Os autores que entendem a incursão do movimento afroequatoriano dentro do Estado como continuidade do corporativismo que caracteriza o Estado equatoriano, observam que o crescimento do aparelho estatal para abordar questões raciais se deu a partir da incorporação de ativistas e acadêmicos do movimento negro visando a formulação de políticas públicas implicando na tutelagem das formas de organização e de manifestação do movimento, por parte do Estado, ao tempo que produz uma ascensão social individual, porém sem grandes ganhos em termos de implementação das políticas, mas com um impacto desmobilizador e esvaziador da organização de base (De La TORRE, 2005; JOHNSON, 2007; RAHIER, 2014; ANTON, 2018).

Ainda, De La Torre (2005) identifica traços paternalistas nesse processo, no sentido de que o Estado, através das suas instituições, oferece uma proteção a indivíduos ou a grupos de pessoas diante das injustiças, mas não produz um questionamento à dominação em termos estruturais e impede o movimento de se organizar no intuito de combater a discriminação estrutural, mas promove aproximações clientelares para pequenos projetos.

Em uma interpretação semelhante, Walsh (2012) entende que a inclusão de afrodescendentes em cargos governamentais durante o governo Correa sugere uma "inclusão representativa" sujeita à visão do Estado e não à lutas coletivas e interesses da comunidade. Uma "inclusão" que não reflete

\footnotetext{
${ }^{8}$ No original: in Ecuador, as in most Latin American nations, citizenship is weak and common people use strategies based on paternalism and corporatism to negotiate access to resources from which they are excluded (De la TORRE, 2005, p. 61).
} 
na diminuição da desigualdade racial, pois de fato em alguns momentos a distância entre brancos e negros com relação à educação superior, emprego e renda tem aumentado. $\mathrm{Na}$ análise de Walsh (2012), esse é um tipo de inclusão representativa e funcional que deixa intactos os problemas históricos e estruturais como o racismo e a dominação racial, mas que beneficia o governo, no sentido de que a visibilidade dos afroequatorianos no governo é apresentada como a nova cara do Estado, a cara da "Revolução Cidadã".

De fato, em entrevista, lideranças dos movimentos sociais revelam que entraram a construir uma agenda junto ao Estado com receios e profundas críticas sobre as possibilidades reais de reparação histórica, meta dos movimentos negros no Equador, uma vez que o discurso do projeto político da "Revolução Cidadã" parecia se limitar a superação da pobreza e a modernização.

Contudo, a participação de indígenas e afrodescendentes na criação de reformas pode, por uma parte, desencadear processos inesperados e fortalecedores que as elites são incapazes de controlar (VAN COTT, 2006), por outra, produzir e afirmar significados político-culturais que os projetos estatais não podem consertar prontamente (HALE, 2005), principalmente quando esses servidores públicos foram também lideranças reconhecidas do movimento afroequatoriano e pressionam para executar a agenda do movimento dentro do Estado. Em certa medida, o movimento afroequatoriano tem conseguido negociar a inclusão da sua agenda e colocar a discussão sobre o racismo, as desigualdades raciais e a necessidade de direitos coletivos e de reparação dentro das instâncias de poder público em uma sociedade governada pela ideologia da mestiçagem (WHITTEN; QUIROGA, 1998).

Em conversa com militantes do movimento afroequatoriano, é possível perceber que a despeito dos limitados ganhos em termos de implementação da política, estes só foram possíveis graças a que o movimento social afroequatoriano aproveitou a janela de oportunidades que a emergência de um governo mais permeável ofereceu às suas demandas. Inclusive, a profissionalização do movimento social afroequatoriano pode ser entendida como um recurso ganho nos últimos anos e que poderia impactar positivamente na manutenção das políticas.

\subsection{CARÁTER DE BASE NO SURGIMENTO DO MOVIMENTO AFROEQUATORIANO}

Antón (2011) parte da teoria dos movimentos sociais (novos movimentos sociais e repertórios da ação coletiva) para discutir o processo organizativo afroequatoriano. $\mathrm{O}$ autor salienta dois fatores 
que permitiriam caracterizá-lo como movimento social: a) a organização, e b) a procura por mudança social. Nesse sentido:

O que compreendo por processo organizativo afroequatoriano é o que se entende como uma rede de organizações e atores sociais (ativistas, intelectuais, simpatizantes e instituições) que compõem estruturalmente a sociedade civil afroequatoriana e que interpelam o Estado e a sociedade por mudanças. Esse processo organizativo é o que se denomina expressão do movimento social afrodescendentes no Equador (ANTÓN, 2011, 85, tradução própria ${ }^{9}$ ).

Muitos dos integrantes do que aqui chamamos de movimento afroequatoriano não se identificam como um movimento social, mas como um processo organizativo. Os argumentos utilizados para questionar que seja um movimento social têm a ver principalmente com a falta de uma posição política nacional unificada. Mas Antón (2011) reconhece essa característica como sendo própria da forma de organização do movimento afroequatoriano, como tendo vários níveis organizativos, sem uma estrutura central reconhecida, e, portanto, sem uma estrutura nacional capaz de falar em nome das organizações nas diferentes províncias, mas com uma ideologia comum que as unem através de redes informais. "[E]sta ideología tiene que ver con principios motivadores de la reivindicación afroecuatoriana: la lucha contra el racismo, la discriminación, la desigualdad socioeconómica y mayor participación política" (ANTÓN, 2011, 128).

Para Antón (2011), o movimento afroequatoriano está conformado por essa pluralidade de organizações de distintos níveis territoriais, de diferentes tamanhos, capacidade organizativa e incidência, que representam distintos interesses (urbanos, camponeses, juvenis, acadêmicos, de mulheres, produtivo). Essas organizações estão formalmente agrupadas sob a figura de Federações por regiões do povo afroequatóriano, mas, na prática, é um processo mais descentralizado e informal movido por laços interpessoais, porém capaz de se integrar em uma agenda tácita de reivindicações como aconteceu com a Constituinte de 2008. Essa forma organizativa tem o problema de tornar as organizações do movimento permeáveis, fáceis de desaparecer ou de serem cooptadas na disputa por recursos. Mas isso não quer dizer que o movimento afroequatoriano seja altamente corporativizado.

A dinâmica de organização e de ação coletiva não depende só das necessidades dos afroequatorianos e dos problemas estruturais das suas comunidades, mas o governo e a cooperação

\footnotetext{
${ }^{9}$ No original: lo que aquí comprendo por proceso organizativo afroecuatoriano es lo que se entiende como una red de organizaciones y actores sociales (activistas, intelectuales, simpatizantes e instituciones) que componen estructuralmente la sociedad civil afroecuatoriana y que interpelan al Estado y a la sociedad por situaciones de cambio. Este proceso organizativo es lo que se denomina expresión del movimiento social afrodescendiente en Ecuador (ANTÓN, 2011, 85).
} 
internacional agem como motivadores da ação coletiva, em parte porque têm recursos, em parte pela janela de oportunidade política (" la agencia que se produce desde el Gobierno y la cooperación internacional se convierte en motivadores de la acción colectiva" (ANTÓN, 2011, 195)) e isso impacta nos repertórios de ação coletiva.

Contudo, muitos dos entrevistados argumentaram que cada instituição que historicamente o Estado tem criado para assuntos dos afroequatorianos tem sido produto do lobby dos ativistas. Assim, a distribuição de recursos para as comunidades, o apoio financeiro para o fortalecimento do movimento afroequatoriano, a criação de instâncias como o CODENPE ou a CODAE foram gestadas ou no interno do movimento, ou pela ação de lideranças do processo organizativo próximas ao Estado ou em execução de cargos públicos.

Em alguns países da região, aconteceu uma sintonia entre o projeto político e o movimento negro, durante os governos da chamada "onda rosa, o que possibilitou ainda que, com múltiplos desafios, a passagem do movimento pelo Estado (LAO-MONTES, 2013). Com a chegada do projeto político da Revolução Cidadã, projeto político de Rafael Correa, Presidente Constitucional do país por dois períodos, entre 2007 e 2017, o movimento afrodescendente tentou participar da construção do Estado intercultural e plurinacional. O movimento conseguiu colocar a noção de que a prática do racismo “impide la concreción de la multiculturalidad como proyecto nacional” (ANTÓN, 2011, 81).

As estratégias políticas nesse período precisaram se adaptar à nova situação política, quer dizer, governos favoráveis à inclusão, mas onde as hierarquias fundadas na raça e a reprodução de desigualdades raciais permaneceram (WALSH, 2012; RAHIER; PROSPER, 2014). O processo de institucionalização das demandas também exigiu do movimento afroequatoriano um papel ativo na formulação e execução das políticas. Em certa medida, o movimento social subministrou ao Estado um corpo de funcionários formado na militância.

Correa indicou afro-equatorianos para posições de visibilidade dentro do seu gabinete e premiou intelectuais afroequatorianos. Aparentemente, essas ações tinham o intuito de mostrar as transformações das prioridades e lealdades do governo (DE LA TORRE; ANTÓN, 2012). A despeito do aumento no número de afrodescendentes no governo, estes não foram postulados por organizações do processo afroequatoriano e, portanto, a sua permanência no governo não tinha o compromisso de representar os interesses das comunidades e das organizações afrodescendentes.

Mais na frente, se apresentam as correntes a partir das quais distintos teóricos tem entendido a relação do movimento afroequatoriano com o Estado, por enquanto é de ressaltar o fato de que a 
nível nacional, o movimento afroequatoriano conseguiu alguns avances legais. Por exemplo, conseguiu aprovar a Ley de Derechos Colectivos de los Pueblos Negros o Afroecuatorianos, publicada no registro oficial no 275 de 22 de maio de 2006 (recentemente derrogada); formular desde a Corporación para el Desarrollo Afroecuatoriano (CODAE) o Plano Nacional contra a Discriminação Racial em 2009; aprovar o Decreto Presidencial 60, que instituiu políticas públicas para combater a desigualdade racial, assinado em 2009. Todas essas inovações legislativas foram desenhadas e impulsionadas por ativistas do movimento afroequatoriano na sua passagem pelo Estado. Contudo, geralmente os direitos obtidos na legislação aprovada permanecem no campo discursivo, com forte limites para a implementação. De modo que, na prática, na vida cotidiana, não se percebem as mudanças.

Com a eleição de Lenin Moreno em 2016 e a ruptura com o projeto político da Revolução Cidadã, o movimento afroequatoriano perde muito do apoio político conquistado. Com uma agenda neoliberal, os afrodescendentes não parecem mais atores políticos relevantes para a gestão de Lenin Moreno. Além disso, e como possível consequência da sua incursão dentro do Estado, o movimento se encontra desarticulado, com pouca capacidade de organização, mas também os sujeitos dentro do movimento têm adquirido experiência e profissionalização no funcionamento do Estado.

\section{CONSIDERAÇÕES FINAIS}

Entendendo o movimento afroequatoriano como um processo organizativo, como seus próprios integrantes o definem, este exemplifica bem a complexidade do processo de politização da identidade e de conformação de um movimento social. Fica evidente que as ações dos movimentos estão em relação ativa com vários atores nacionais e internacionais, e que vários outros processos que tendem a influenciar as possibilidades de organização e de ação coletiva (ANTÓN, 2011).

O que se desprende da análise é que o contexto nacional influencia nas características que o movimento assume, os casos de violência racial policial, as reformas constituintes, a criação de oficinas públicas e a maior inclusão de afroequatorianos nas estruturas do Estado, a consolidação do movimento indígena no país, os relatos de Estado-Nação, os projetos de multinacionais para grupos étnicos são fatores que influenciaram as possibilidades de organização uma vez que criaram cenários específicos para as lutas do movimento afroequatoriano. $O$ contexto internacional também exerce grande influência. O movimento afroequatoriano se insere dentro das lutas da diáspora africana nas 
MONAGREDA, J. K. Da incursão do movimento afroequatoriano no estado: possibilidades e limitaçoes. DOI:

http://dx.doi.org/10.5380/recp.v10i2.70425

Américas e, nesse sentido, tem consolidado um discurso e uma agenda de atuação como afrodescendentes na América Latina forjado nos encontros internacionais, mas também nas possibilidades de articulação e de transnacionalização dos discursos e das lutas afrodiaspóricas, que ofereceram a III Conferência Internacional contra o racismo em Durban. No caso equatoriano, em particular, a proximidade com o processo de comunidades negras da Colômbia também exerceu grande influência na procura pelo reconhecimento como povo, bem como a agenda da cooperação internacional.

Assim, as organizações do movimento afroequatoriano também assumem as formas necessárias e possíveis para enfrentar os desafios de se mobilizar contra o racismo (vide as manifestações), gerir recursos e executar projetos (vide as ONGs profissionais), e/ou formular políticas públicas (vide a criação de uma institucionalidade para afroequatorianos e a inserção de algumas figuras do movimento dentro do Estado).

Ainda sendo um movimento pouco estruturado e permeável, tem conseguido se organizar na procura de reivindicações coletivas. As conquistas constitucionais (reconhecimento do status de povo, direitos coletivos, o embasamento constitucional para políticas afirmativas e políticas de reparação) e a aprovação de leis e planos nacionais revelam que o projeto político do movimento afroequatoriano está para além da ocupação de cargos públicos, ainda que exista o risco da cooptação. Aliás, em entrevista, integrantes do movimento afroequatoriano afirmaram que entendem que é responsabilidade do Estado a luta contra a desigualdade racial.

O Estado funciona como adversário, mas também como patrocinador da organização dos movimentos sociais. O Estado é o objeto da protesta. Tem a obrigação constitucional de garantir os direitos, portanto, as organizações demandam ao Estado suas reivindicações, mas é também o Estado quem dispõe de recursos para financiar muitas das atividades do movimento e isso é lido como parte das suas responsabilidades.

Alguns pesquisadores afirmam que o movimento negro do Equador não tem grande capacidade de ação coletiva, mas os integrantes do movimento entrevistados analisam sua ação como preferencialmente de cabildeo ou lobby. Em qualquer caso, o movimento afroequatoriano tem conseguido em distintos momentos resposta do Estado graças a uma estratégia não-confrontacional (DE LA TORRE; ANTÓN, 2012), principalmente pela estratégia de inclusão dos seus líderes no aparato estatal, ainda que esses líderes não foram postulados pelo movimento. Após as entrevistas, é 
possível afirmar que a trajetória pessoal dos atores chave do movimento afroequatoriano explica em grande parte as conquistas alcançadas.

Contudo, Antón (2011), avaliando o movimento afroequatoriano até 2009, afirma que, em parte, as mudanças constitucionais ou legais não tenham se implementado com sucesso se deve a que o movimento social não tem sido hábil na negociação, e "en la ganancia de capital social suficiente para que el Estado" (ANTÓN, 2011, 249) disponibilize um plano orçamentário que permita executar as políticas de fato.

Certamente, a capacidade de participação nas organizações do movimento se vê afetada pela falta de recursos econômicos e a pobreza nas comunidades afrodescendentes. Os entrevistados mostraram preocupação sobre as dificuldades colocadas pelas limitações financeiras dos integrantes do movimento para a mobilização. Contudo, a falta de "vontade política" foi talvez a causa mais enunciada. Em parte, os entrevistados identificam uma falta de compromisso entre os membros do Estado que realmente detém o poder político para alavancar as mudanças e, por outra, percebem que a inclusão pregada não tem afetado os elementos estruturais da exclusão, nem tem implicado numa democratização da administração do poder.

O caráter pouco institucionalizado das mudanças nos faze supor que mesmo com a garantia constitucional, os tímidos avanços em matéria de direitos coletivos, ações afirmativas e luta contra a discriminação racial, dependem em grande medida da permeabilidade dos governos a esses temas e da discricionariedade do corpo de funcionários públicos em cada gestão.

\section{REFERÊNCIAS}

ANTÓN, J. (2011). El proceso organizativo afroecuatoriano: 1979-2009. Quito: FLACSO.

LAO-MONTES, A. (2013). Empoderamiento, descolonización y democracia sustantiva. Afinando principios ético-políticos para las diásporas Afroamericanas. CS, Cali, no. 12, p. 53-84.

DE LA TORRE, C., ANTÓN, J. (2012). The Afro-Ecuadorian Social Movement: Between Empowerment and Co-optation. In: RAHIER, J. Black social movements in Latin-America: from monocultural mestizaje to multiculturalism. New York: Palgrave Macmillan.

DE LA TORRE, C. (2005). Afro-Ecuadorian Responses to Racism: Between Citizenship and Corporatism. In: DZIDZIENYO, A., OBOLER, S. Neither Enemies nor Friends: Latinos, Blacks, AfroLatinos. New York: Palgrave Macmillan. 
MONAGREDA, J. K. Da incursão do movimento afroequatoriano no estado: possibilidades e limitaçoes. DOI:

http://dx.doi.org/10.5380/recp.v10i2.70425

HALE, C. (2002). Does multiculturalismo menace: Governance, Cultural Rights and the Politics of Identity in Guatemala. Journal of Latin American Studies, n 34, p. 485-524.

HOOKER, J. (2005). Indigenous Inclusion/Black Exclusion: Race, Ethnicity and Multicultural Citizenship in Latin America. Journal of Latin American Studies, n 37, p. 285-310.

KINGDON, J. (1984). Agendas, alternatives and public policies. Boston: Little Brownp.

KLYMICKA, W. (1995). Multicultural Citizenship: A Liberal Theory of Minority Rights. Clarendon Press.

LEÓN, E., SANTACRUZ, L. (2013). Saberes propios, religiosidad y luchas de existencia afroecuatoriana. In: HALE, C., STEPHEN, L. Otros saberes: collaborative research on indigenous and Afrodescendant cultural politics. Santa Fé: SARPRESS.

LOVEMAN, M. (2014). National Colors: Racial classification and the State in Latin America. Oxford University Press.

LUCERO, J. (2012). Indigenous Politics: Between Democracy and Danger. In: KINGSTONE, P., YASHAR, D. Routledge bandbook of Latin American politics. Routledge.

RAHIER, J., PROSPER, M. (2014). Chapter 4: Afrodescendants, the Multicultural Turn and the "New" Latin American Constitutions and Other Special Legislations: Particularities of the Andean Region. In: RAHIER, J. Blackness in the Andes Ethnographic Vignettes of Cultural Politics in the Time of Multiculturalism. New York: Palgraven Macmillan.

RAHIER, J. (2012). Interview with María Alexandra Ocles Padilla, Former Minister, Secretaría de Pueblos, Movimientos Sociales y Participación Ciudadana, Ecuador. by Jean Muteba Rahier with Mamyrah A. Dougé-Prosper. In: RAHIER, J. Black social movements in Latin-America: from monocultural mestizaje to multiculturalism. New York: Palgrave Macmillan.

RIBEIRO, M. (2012). As politicas de igualdade racial: Reflexões e perspectivas. São Paulo: Fundação Perseu Abramo.

VAN COTT, D. L. (2009). The friendly liquidation of the past: the politics of diversity in Latin America. Pittsburgh: University of Pittsburgh Press. Digital Research Library 2009-12-22. Disponível em: http://www.upress.pitt.edu/BookDetails.aspx?bookId=35215.

VAN COTT, D. L. (2008). Radical Democracy in the Andes. Cambridge: University Press.

WALSH, C. (2012). Afro In/Exclusion, Resistance, and the "Progressive" State (De)Colonial Struggles, Questions, and Reflections. In: RAHIER, J. Black social movements in Latin-America: from monocultural mestizaje to multiculturalism. New York: Palgrave Macmillan.

WHITTEN, N., QUIROGA, D. (1998). "To rescue national dignity": Blackness as quality of nationalist creativity in Ecuador. In: WHITTEN, N., TORRES, A. Blackness in Latin America and the Caribbean. Indiana University Press. 